\title{
Foreign contributors hold fate of two SSC detectors
}

Dallas. US physicists are crisscrossing the world in an unprecedented search for ways to reduce the cost of the two detectors they hope to build for the Superconducting Super Collider (SSC). Their travels to such non-scientific outposts as Albania and Ecuador will test the idea that researchers and industrialists in other countries are eager to share with the United States the cost of discovering the underlying forces of nature.

Until this year, the question of foreign contributions to the SSC has been largely a philosophical debate about whether the United States is capable of attracting significant international support for a major research project. But for the scientists who must build the two massive detectors known as SDC (Solenoidal Detector Collaboration) and GEM (Gamma-ElectronMuon) - that will carry out the laboratory's experimental programme, the issue has suddenly become very real: if other countries do not pledge nearly half of the $\$ 500$ million or so that each detector is expected to cost, that programme will have to be trimmed. It is even possible that only one of the detectors will be built.

"The amount available [from the US Department of Energy] is not sufficient", says George Trilling of Lawrence Berkeley Laboratory and the University of California at Berkeley. "Even with outside help, it's not clear that we will have enough."

With construction workers poised to build the 54-mile-long tunnel that will house the giant machine and with magnet developers increasingly confident that their creations will steer two opposing streams of protons toward their mutual annihilation, attention is turning to the two detectors that will record the actual science to be carried out 250 feet beneath the rolling Texas plains. As tall as an eight-storey building and weighing some 50,000 tons, each detector involves a team of almost 1,000 scientists and will take until 1999 to finish.

Part of the problem is that the required contributions are an order of magnitude beyond any previous collaborations at such accelerator facilities as Fermilab in Chicago and CERN, the European Laboratory for Particle Physics in Geneva. "It's not something that high-energy physicists can decide to do on their own", says Trilling. "They have to work closely with their funding agencies, and that takes a long time."

But some of the problem is of their own making. The $\$ 8,250$ million price for the SSC - a figure that the Department of Energy (DOE) has promised Congress it will not exceed - includes only $\$ 550$ million to build the two major detectors. As each will cost that much, some observers believe that the SSC officials made a mistake in deliberately underpricing their research programme.

The typical collaboration features experimental physicists who share an intellectual curiosity, and who may have already worked together. That is the impetus for participation by scientists from Britain, Italy, France, Germany, Russia, China, India, Brazil and more than a dozen other countries. But the quest for financial support has also taken GEM scientists to Albania and its centuries-old tradition of fabricating copper, as well as to Ecuador and its heritage of fine woven goods.

"What we want from the Albanians is pretty straightforward”, explains Bill
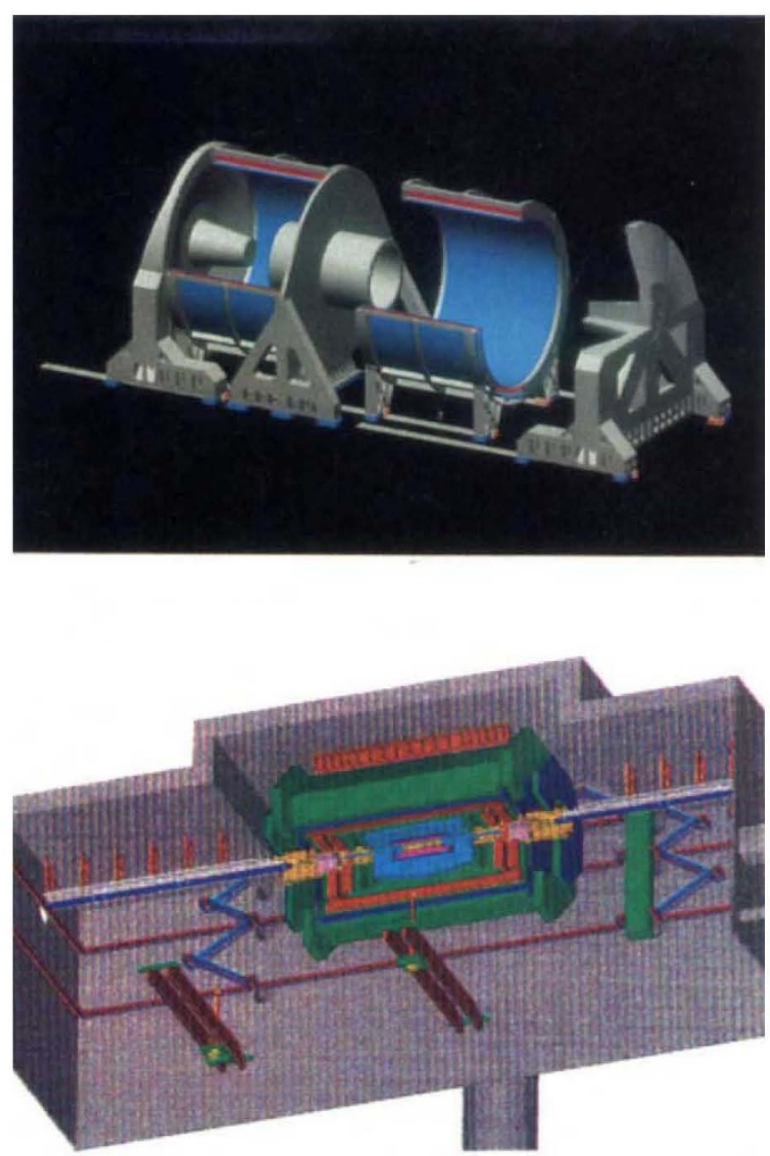

The GEM (top) and SDC (bottom) detectors require international funding.
Worstell of Boston University, whose colleague, Larry Sulak, has visited the country in the hope of striking a deal with the former outcast nation suddenly eager to build ties with the West. "Any competent machine shop would be capable of doing it. But we could buy their copper at internal prices, and the cost of labour would be very low."

Although the component that the Albanians might fabricate - some 940 obelisks of copper sheeting, each 1.5 metres tall and weighing more than a ton - costs only $\$ 11$ million by US estimates, GEM hopes that foreign contributions will add up to savings of some $\$ 60$ million in the overall cost of the $\$ 150$-million hadron calorimeter. Another potential saving could come from enlisting Ecuadorian labour to insert fibre optic cables into tubes that fit into grooves in the copper sheeting. "Our part of the detector is more easily exportable because much of it is relatively low-tech", says Worstell.

Roy Schwitters, director of the SSC laboratory, says that he is confident that other countries will make substantial contributions to the detectors. But the political and financial obstacles are formidable. Japan's decision, for example, is linked to its overall support for the SSC. If it pays for a portion of the accelerator and the magnets, it is likely to make a sizeable contribution to the detectors as well. But a decision not to invest in the machine itself would dim its interest in the detectors. The European teams, on the other hand, are expected to line up behind CERN's plan to build a large hadron collider, leaving little for the SSC.

Trilling and other members of both collaborations hope to develop a credible plan about the expected foreign contributors, but they doubt that such decisions will be made as early as DOE officials would like.

"We want to start construction early next year", Trilling says. "But I don't think that we'll have commitments by then."

If the expected support does not materialize, SSC officials will have to face the prospect of doing less science, either by eliminating one or more elements of each detector or moving ahead with only one detector. Collaborators on GEM acknowledge their late start - GEM won approval last summer, while SDC received the go-ahead several months earlier - has put them temporarily behind in the race to nail down foreign contributors.

Schwitters, of course, is not about to reveal his plans. He believes that the laboratory's budget for its experimental programme is adequate, and that international contributions are essential. "We've said what the SSC will cost, and we're not going to budge from that", he says.

Jeffrey Mervis 